BMJ Open

Sport \&

Exercise

Medicine

\section{High-intensity interval training in haemodialysis patients: a pilot randomised controlled trial}

To cite: Nilsson BB, Bunæs-Næss H, Edvardsen E, et al. High-intensity interval training in haemodialysis patients: a pilot randomised controlled trial. BMJ Open Sport \& Exercise Medicine 2019;5:e000617. doi:10.1136/ bmjsem-2019-000617

Accepted 13 0ctober 2019

\section{Check for updates}

(c) Author(s) (or their employer(s)) 2019. Re-use permitted under CC BY-NC. No commercial re-use. See rights and permissions. Published by BMJ

${ }^{1}$ Department of Clinical Services, Oslo University Hospital, Oslo, Norway

${ }^{2}$ Faculty of Health Sciences, Oslo Metropolitan University, 0slo, Norway

${ }^{3}$ Department of Pulmonary Medicine, Oslo University Hospital, Oslo, Norway

${ }^{4}$ Department of Nephrology, Oslo University Hospital, Oslo, Norway

Correspondence to Dr Birgitta Blakstad Nilsson; biblni@oslomet.no

\section{ABSTRACT}

Objectives Patients with end-stage renal disease (ESRD) undergoing haemodialysis (HD) have significantly reduced cardiorespiratory fitness and health-related quality of life (HRQoL). Our hypothesis was that high-intensity interval training (HIIT) is a feasible and safe form of exercise during HD and that HIIT would elicit greater change in cardiorespiratory fitness and HRQD compared with moderate-intensity continuous training (MICT).

Methods Twenty patients were randomised to either HIIT $(n=6)$, MICT ( $n=8)$ (two times a week within 22 weeks) or usual care $(n=6)$. Feasibility was assessed by session attendance and adherence to exercise intensity. Safety was assessed by adverse event reporting. Efficacy was determined from change in peak oxygen uptake $\left(\mathrm{VO}_{2 \text { peak }}\right)$, 6 min walk distance and a HRQoL questionnaire (the COOP-WONCA chart).

Results Eleven patients (55\%) completed premeasurements and postmeasurements. The main reason for drop-out was due to kidney transplant during follow-up. The patients completed the same number of sessions in each group and adhered to the target heart rates after habituation. There were no adverse events. In the HIIT group, two of the three patients increased $\mathrm{VO}_{2 \text { peak }}$ by $46 \%$ and $53 \%$, respectively. Three of the five patients in the MICT group increased their $\mathrm{VO}_{2 \text { peak }}$ by $6 \%, 18 \%$ and $36 \%$, respectively.

Conclusions This pilot study demonstrated that HIIT is a feasible and safe exercise model for intradialytic exercise in patients undergoing HD. There might be a considerable potential of intradialytic HIIT in patients undergoing HD. Further studies with larger sample sizes are needed to determine if HIIT is an optimal approach in patients with ESRD undergoing $H D$.

Trial registration number NCT01728415.

\section{INTRODUCTION}

Patients with end-stage renal disease undergoing haemodialysis (HD) have lower cardiorespiratory fitness, poorer healthrelated quality of life (HRQoL) and functional impairment compared with age-matched individuals in the general population. ${ }^{12}$ Exercise has a significant impact on these factors in patients undergoing HD. ${ }^{3}$ However, HD is a time-consuming procedure that takes at
What are the new findings?

Supervised intradialytic high-intensity interval training (HIIT) is safe and feasible in medically stable patients with end-stage renal disease.

- Our results indicate that both HIIT and moderateintensity continuous training (MICT) can lead to a clinically significant increase in cardiorespiratory fitness and quality of life.

- In haemodialysis (HD) populations that include patients waiting for kidney transplant, it seems important to take into account the possible high drop-out rate during follow-up.

- Until more evidence on HIIT during HD is available, a combination of HIIT and MICT seems beneficial to improve cardiorespiratory fitness.

least 4 hours, three to four times a week, and exercise during HD (intradialytic exercise) has shown to be the most feasible and applicable option for these patients. ${ }^{4}$ It provides a unique opportunity to combine exercise with medical treatment in a highly monitored environment where potential complications can be detected and treated immediately. In addition, time is used efficiently, and it has been shown to increase adherence and compliance compared with exercise between HD sessions. ${ }^{4} 5$ Despite this, intradialytic exercise is still not a routine treatment for patients undergoing HD, perhaps because of uncertainty about the best modality for the patient group ${ }^{67}$ or because of lack of information and lack of medical staff knowledge regarding the positive effects of intradialytic exercise. Results from a systematic review with 24 randomised controlled trials (RCTs) showed that intradialytic exercise significantly improves cardiorespiratory fitness, physical performance and self-reported physical function in HRQoL questionnaires. ${ }^{8}$ In general, high-intensity interval training (HIIT) has repeatedly been proven to have superior positive effects and health benefits compared with moderate-intensity continuous training 
(MICT). This applies to both healthy subjects ${ }^{9}$ and patients with metabolic syndrome, ${ }^{10}$ coronary artery disease ${ }^{11}$ and heart failure. ${ }^{12} 13$ A recent pilot study evaluated the feasibility, safety and efficacy of HIIT in patients with chronic kidney disease. ${ }^{14}$ This study demonstrated that HIIT is feasible and safe for patients with chronic kidney disease, but patients undergoing HD were not included. Whether HIIT is feasible and safe for dialysis populations, however, has not yet been evaluated. In addition, there is a lack of knowledge regarding the efficacy of HIIT ( $\geq 85 \%$ of peak heart rate) versus MICT in patients undergoing HD. Therefore, the aim of this study was to evaluate the feasibility, safety and efficacy of intradialytic HIIT in patients undergoing HD through a randomised controlled pilot study. Our hypothesis was that HIIT is a feasible and safe form of intradialytic exercise and that HIIT would elicit greater change in cardiorespiratory fitness and quality of life compared with MICT.

\section{METHODS \\ Study design}

In this single-blinded three-armed RCT pilot trial, patients were randomised into one of three groups (figure 1) using a computer-generated randomisation list generated by a researcher independent of the study in a 1:1:1 ratio. Concealed envelopes with subsequent numbers were kept in a locked drawer on the switchboard and were withdrawn consecutively after the baseline tests. The study is registered in ClinicalTrial.gov.
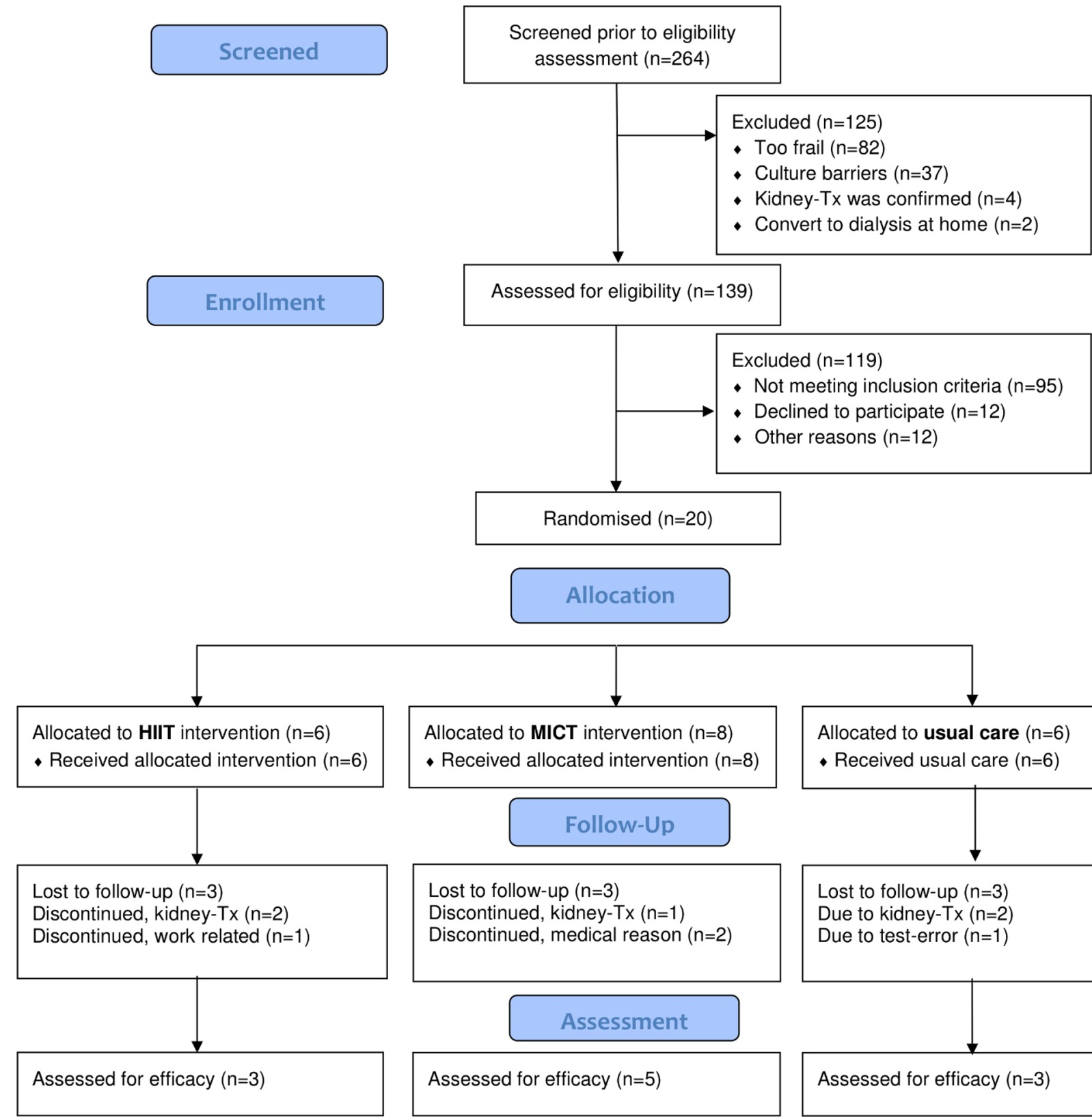

\section{Allocation}

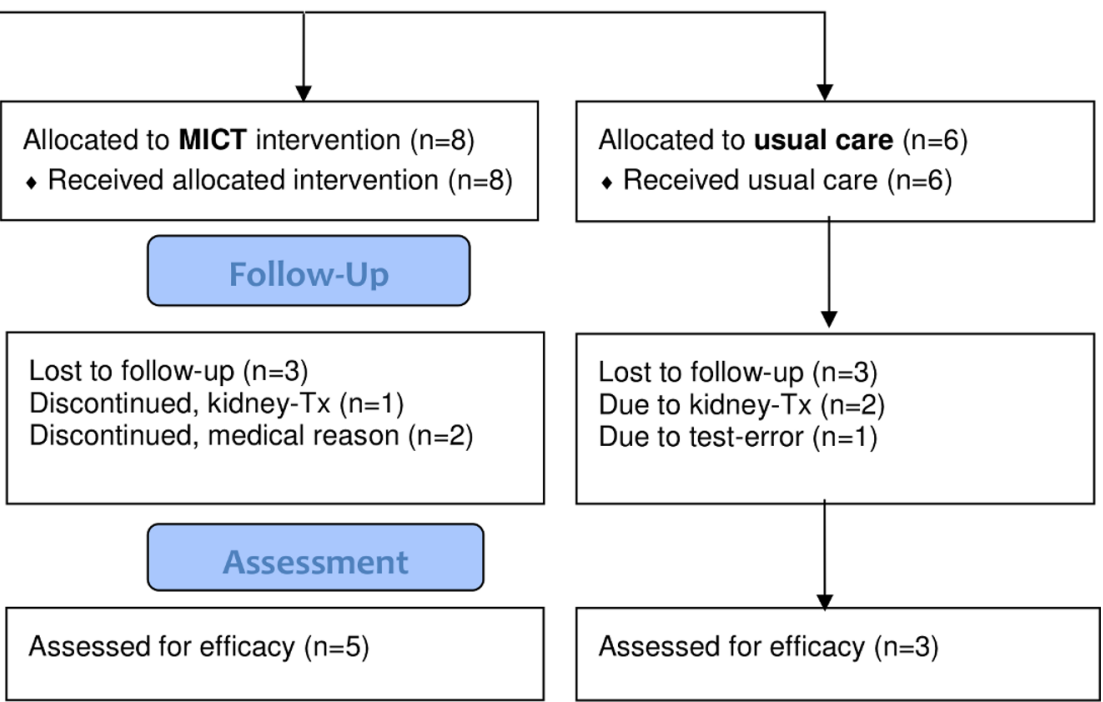

Figure 1 Consort flowchart. HIIT, high-intensity interval training; Kidney-Tx, kidney transplant; MICT, moderate-intensity continuous training. 
Inclusion criteria were medically stable patients in HD for $\geq 3$ months and aged between 20 and 75 years. Exclusion criteria were acute infection, unstable angina pectoris, severe arrhythmias, uncontrolled hypertension (systolic blood pressure (BP) $>180 \mathrm{~mm} \mathrm{Hg}$ and/or diastolic $\mathrm{BP}>105 \mathrm{~mm} \mathrm{Hg})$, hyperkalemia $(>6 \mathrm{mmol} / \mathrm{L})$, uncontrolled diabetes, wheelchair dependence, arteriovenous thigh graft access and $\mathrm{Hb}<90 \mathrm{~g} / \mathrm{dL}$.

\section{Patient and public involvement (PPI)}

As no funds or time were allocated for PPI, participants were unable to be involved in study design stages. However, patients at our hospital have been involved in trying various bed-cycle ergometers suitable for the HIIT intervention.

\section{Exercise intervention}

The exercise intervention was performed using a bedcycle ergometer (MOTOmed letto2, Reck, Germany) positioned in front of the patients' dialysis chair. The patients in the exercise groups performed either supervised HIIT or MICT cycling two times a week, for a total of 32 sessions over 16-22 weeks. The exercise intervention lasted $45 \mathrm{~min}$ and started during the first hour of dialysis. All patients were individually supervised by an experienced physiotherapist. During the exercise, the heart rate was continuously evaluated with a heart rate monitor (SUUNTO Ambit 2) (suunto.com), and Borg scale (ranging 6-20) ${ }^{15}$ was registered. Completion of $70 \%$ of the prescribed exercise sessions was considered as training per protocol. While planning this study, there were no universal criteria or framework for delivery of HIIT in the clinical population. ${ }^{16}$ At our hospital, we have significant results in both patients with chronic heart failure and coronary disease, with the Norwegian Ullevaal model, ${ }^{17} 18$ a HIIT model consisting of three intensive intervals and active brakes between the intervals. Musculoskeletal risk may be increased in patients with chronic kidney disease as a result of uraemic myopathy and bone disease, ${ }^{7}$ and therefore, every session in both exercise groups started with up to 18 min warm up at low-to-moderate intensity.

\section{HIIT group}

After warm up, every session continued with three exercise intervals lasting $3 \mathrm{~min}$ each, at an exercise intensity of 85\%-95\% of HRpeak, equalling 15-17 on the Borg scale. Each interval was separated by 4 min of active breaks at an intensity of $60 \%-70 \%$ of HRpeak. The last exercise interval was followed by a cool down period of up to $10 \mathrm{~min}$.

\section{MICT group}

Followed by warm-up, every session consisted of cycling at low-to-moderate exercise intensity of $50 \%-60 \%$ of HRpeak, representing 11-13 on the Borg scale for $45 \mathrm{~min}$ (including warm up).

The usual care group underwent standard HD treatment without any supervised exercise.

\section{Outcomes}

Feasibility was assessed via adherence to the exercise prescription. Adherence included both adherence to the prescribed session and the ability to meet the intensity targets set in each session. During the exercise, the heart rate was continuously evaluated with a heart rate monitor (SUUNTO Ambit 2) (suunto.com), and Borg scale (ranging 6-20) was registered. ${ }^{15}$

To evaluate safety, all patients were told to report any issues or problems that occurred during or following the exercise sessions. The exercise sessions were conducted in a highly monitored environment, and $\mathrm{BP}$ was continuously monitored with the HD machine (remaining at $\geq 90 / 50 \mathrm{~mm} \mathrm{Hg}$ and not increasing to $\geq 200 / 100 \mathrm{~mm} \mathrm{Hg}$ ).

Efficacy measures were performed at baseline and the week after completed intervention. Investigators who were blinded to clinical data and group assignment of patients carried out all follow-up tests. All patients underwent a high-tech cardiopulmonary exercise test (CPET) by a trained exercise physiologist for measurement of the $\mathrm{VO}_{\text {2peak }}$ on a cycle ergometer (Lode Corival Ergometer exercise bike, Groningen, Netherlands) under the supervision of a medical doctor. The load increased by 10 or 15 $\mathrm{W}$ each minute until exhaustion based on the predicted fitness level. The gas exchange and ventilatory variables were continuously measured breath-by-breath and analysed using a Sensor Medics metabolic system (Vmax 229 SensorMedics, Yorba Linda, California, USA). The highest $\mathrm{VO}_{2}$ sampled in $30 \mathrm{~s}$ was recorded as $\mathrm{VO}_{2 \text { peak }}$. Heart rate was measured through a 12-lead ECG (Cardiosoft, GE Marquette Medical Systems, Milwaukee, Wisconsin, USA). HRpeak was estimated as the highest recorded heart rate plus five beats. ${ }^{19}$ The rating of perceived exertion was obtained by the Borg scale (ranging 6-20). ${ }^{15}$

Functional capacity was evaluated by the 6 min walk test (6MWT) according to guidelines,${ }^{20}$ in a marked corridor at the hospital. The patient was instructed to walk alone along the hallway at his or her own pace, attempting to cover as great a distance as possible within $6 \mathrm{~min}$. The test is widely used in patients with chronic diseases, ${ }^{21-23}$ including those with chronic kidney disease. ${ }^{5425} \mathrm{HRQOL}$ was assessed using the Norwegian version of the COOPWONCA charts. ${ }^{26}$ The chart is validated for patients with chronic kidney disease, ${ }^{27}$ and is commonly used for monitoring change in functional status over time, and/or measuring the outcomes of interventions. ${ }^{28}$ COOP-WONCA is a generic questionnaire for evaluation of HRQoL, consisting of six dimensions: physical fitness, feelings, daily activities, social activities, changes in health and health condition. Each dimension is illustrated pictorially, numerically and in writing, inquiring about the patient's status during the past 2 weeks. The response categories are scored from 1 to 5 , with higher scores indicating worse HRQoL. A change of 1 is defined to be a clinically meaningful change. At retest the fifth dimension was reworded asking, 'How do you rate your overall health compared with 16 weeks ago?' instead of '[...] to 2 weeks ago?' 
Table 1 Baseline characteristics of the included patients

\begin{tabular}{|c|c|c|c|c|}
\hline Variables & $\begin{array}{l}\text { All } \\
(\mathrm{N}=20)\end{array}$ & $\begin{array}{l}\text { HIIT } \\
(n=6)\end{array}$ & $\begin{array}{l}\text { MICT } \\
(n=8)\end{array}$ & $\begin{array}{l}\text { Usual care } \\
(n=6)\end{array}$ \\
\hline \multicolumn{5}{|l|}{ Median (min-max) } \\
\hline Male, n (\%) & $17(85)$ & $6(100)$ & $7(88)$ & $4(67)$ \\
\hline Age (years) & $59.5(25-69)$ & $59.5(55-67)$ & $57(25-68)$ & $67(51-69)$ \\
\hline Weight (kg) & $71(53-136)$ & $82(63.5-118)$ & $72(57-136)$ & $68(53-114)$ \\
\hline BMI & $24.3(20-39)$ & $26.6(22.5-35.5)$ & $24(20-38)$ & $23(21-39)$ \\
\hline Caucasian, n (\%) & $10(50)$ & $3(50)$ & $4(50)$ & $3(50)$ \\
\hline Smoking, $\mathrm{n}(\%)$ & $2(10)$ & 0 & $2(25)$ & 0 \\
\hline Time in HD (months) & $15(3-46)$ & $9.5(3-46)$ & $15,5(3-34)$ & $15(4-20)$ \\
\hline $\mathrm{Hb}(\mathrm{g} / \mathrm{L})$ & $11(8-13.2)$ & $10.65(8.1-13.2)$ & $11.1(8.9-12.3)$ & $11.05(9.10-13.0)$ \\
\hline \multicolumn{5}{|l|}{ Aetiology, n (\%) } \\
\hline Hypertension & $9(45)$ & $2(33)$ & $3(38)$ & $4(67)$ \\
\hline Chronic glomerulonephritis & $5(25)$ & $2(33)$ & $3(38)$ & 0 \\
\hline Diabetes mellitus & $4(20)$ & $3(50)$ & 0 & $1(17)$ \\
\hline Polycystic kidney disease & $2(10)$ & 0 & $1(13)$ & $1(17)$ \\
\hline \multicolumn{5}{|l|}{ Physical function } \\
\hline $\mathrm{VO}_{2 \text { peak }}(\mathrm{mL} / \mathrm{kg} / \mathrm{min})$ & $14.9(9.6-33.6)$ & $14.9(13.7-19.6)$ & $14.2(10.4-33.6)$ & $14.4(9.6-21.1)$ \\
\hline 6MWT (m) & $439.5(218-658)$ & $466(338-658)$ & $403(218-598)$ & $424(288-498)$ \\
\hline Walk independently, n (\%) & $18(90)$ & $6(100)$ & $7(88)$ & $5(83)$ \\
\hline Overall health $(1-5)^{\star}$ & $3(1-4)$ & $3.5(2-4)$ & $3(2-4)$ & $2.5(1-3)$ \\
\hline
\end{tabular}

${ }^{\star}$ Evaluated by COOP-WONCA; 1 =best score.

$\mathrm{BMI}$, body mass index; $\mathrm{Hb}$, haemoglobin; $\mathrm{HD}$, haemodialysis;HIIT, high-intensity interval training; MICT, moderate-intensity continuous training; $6 \mathrm{MWT}$, Sixmin walk test; $\mathrm{VO}_{\text {2peak }}$, peak oxygen uptake.

\section{Data analysis}

No formal sample size calculation was performed for this pilot study, as the study was not designed to show statistical significance or statistical power. Due to the small sample size, the results were expressed as individual changes and baseline characteristics as median (with range) for continuous data, and frequencies and percentages for categorical data. All analyses were conducted in Statistical Package for Social Science V.25.

\section{RESULTS}

From October 2012 to December 2014, all patients undergoing HD within the specified centre were screened for eligibility $(n=264)$. In total, 20 participants were randomised to either the HIIT group $(n=6)$, the MICT group $(n=8)$ or the usual care group $(n=6)$ (figure 1$)$. This represents a proportion of $7.6 \%$ of patients screened $(20 / 264)$. The baseline characteristics of the patients are shown in table 1.

Both intervention groups completed a median of 32 (29-32) exercise sessions within 22 weeks. All patients in the HIIT group achieved their target heart rate and/or Borg scale score of 15-17 in a minimum of one interval of the completed sessions. Three patients in each group $(n=9)$ were not retested and/or included in the analysis for the following reasons: kidney transplant during follow-up $(n=5)$, work-related $(n=1)$, medical reasons $(n=2)$ and technical error during the CPET $(n=1)$. The results of the individual changes in $\mathrm{VO}_{2 \text { peak }}$ and $6 \mathrm{MWT}$ for each patient are presented in figure 2 and table 2 . In the HIIT group, two out of three patients increased in $\mathrm{VO}_{2 \text { peak }}$ by $46 \%$ and $53 \%$, respectively, and three out of five patients in the MICT group increased by $6 \%, 18 \%$ and $36 \%$, respectively. All the patients in the HIIT group had an improved HRQoL in $\geq 3$ dimensions. Of the five patients in the MICT group, four patients improved in $\geq 2$ dimensions (IDs 4, 5, 6 and 8 ). The results of the individual changes in COOP-WONCA for each patient are presented in table 3 .

\section{DISCUSSION}

To our knowledge, the present study is the first to evaluate intradialytic HIIT in patients undergoing HD. The results of this small pilot study indicate that HIIT is feasible during HD. All patients in the HIIT group had low cardiorespiratory fitness $\left(\mathrm{VO}_{2 \text { peak }}<20 \mathrm{~mL} / \mathrm{kg} / \mathrm{min}\right)$, and the main challenge was to motivate the patients to exercise for $45 \mathrm{~min}$. Furthermore, we had to adjust the exercise sessions for up to 6 weeks before we could record exercise per protocol. It was, however the same challenge in the MICT group. A more gradual approach would have been more appropriate. Another challenge in this population is patient comorbidity and intercurrent illness, and the large interindividual and intraindividual variability. ${ }^{7}$ 


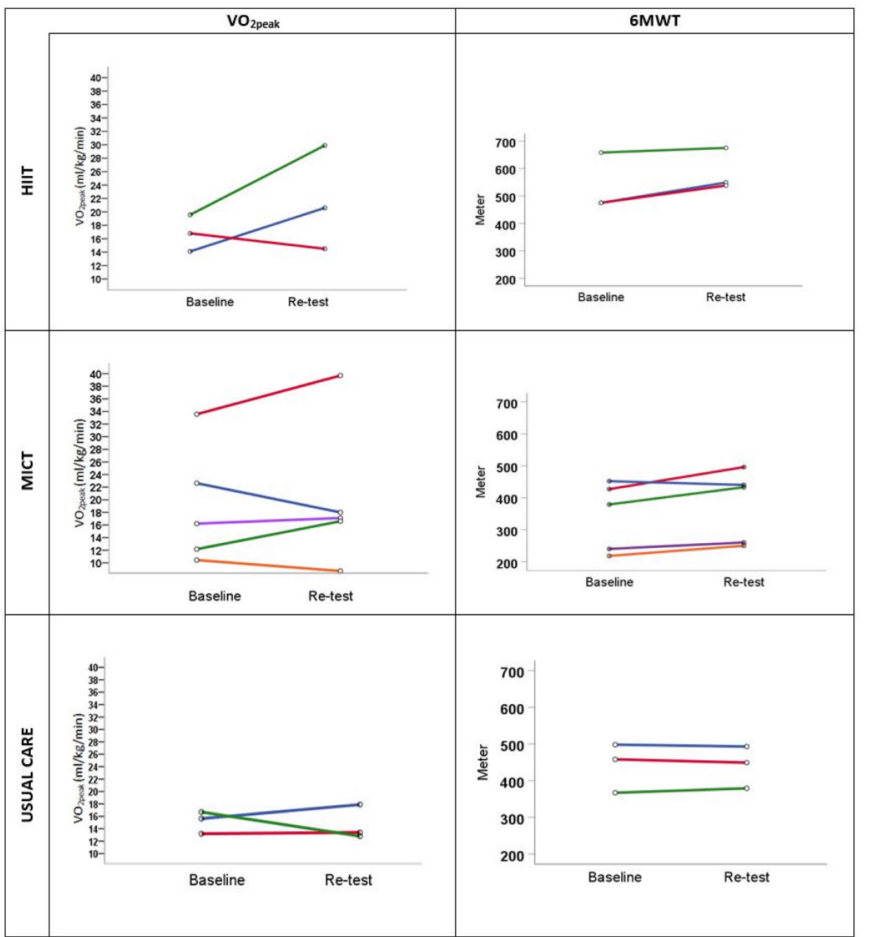

Figure 2 Individual changes in physical fitness. HIIT, high-intensity interval training; MICT, moderate-intensity continuous training; $\mathrm{VO}_{2 \text { peak }}$, peak oxygen uptake; $6 \mathrm{MWT}$, 6 min walk test.

Due to the disease burden, several of the patients had unwanted breaks (intercurrent acute illness) during the training period. The number of breaks was recorded. In case of missed sessions due to intercurrent illness (not medically stable for exercise), the number of exercise sessions was extended up to 32 session within 20 weeks. However, the overall training compliance in terms of training attendance was excellent, indicating a high motivation to perform HIIT during HD. In addition, all patients in the HIIT group achieved their target heart rate and/or Borg scale score of 15-17 in a minimum of one interval of the completed sessions. The patient, who increased $\mathrm{VO}_{\text {2peak }}$ with $>10 \mathrm{~mL} / \mathrm{kg} / \mathrm{min}$ (ID 3), achieved the target heart rate in two or three intervals, in all 32 sessions. He expressed great benefit of supervision by the physiotherapist. This is in line with a qualitative study describing that one of the most important motivators was support from friends, family and healthcare providers. ${ }^{29}$

The HIIT intervention was well tolerated, and no adverse events were reported, indicating that HIIT may be safely performed during HD. All patients underwent CPET for risk stratification and were supervised during each exercise sessions. Thus, to ensure patient safety, we recommend that implementation of intradialytic HIIT be under the supervision of a physiotherapist, in addition to a workload test before exercise. One patient had to interrupt the test because of hypotension and was retested and haemodynamically cleared before being included in the study.

The patient population was complex and it was challenging to recruit patients to this study due to patient multimorbidity. Out of 20 randomised patients, only 11 patients completed the study per protocol. The main reason for drop-out was kidney transplant during follow-up $(n=5)$ and not adverse events or the exercise. In general, kidney transplantation in Norway is offered to all patients considered to benefit, with no strict upper age limit. The median time on the waiting list in 2016 was 10.5 months..$^{30}$ About $50 \%$ of the HD population in Norway is not offered a kidney transplant because of comorbidities and expected lifetime of less than 2 years. ${ }^{30}$

The sample size is sufficient to assess a trend in exercise response after intradialytic exercise at two different training intensities. It is too small, however, to evaluate between-group differences due to low statistical power.

HIIT has been previously proven to increase cardiorespiratory fitness significantly and is established as a

Table 2 Individual changes in physical fitness

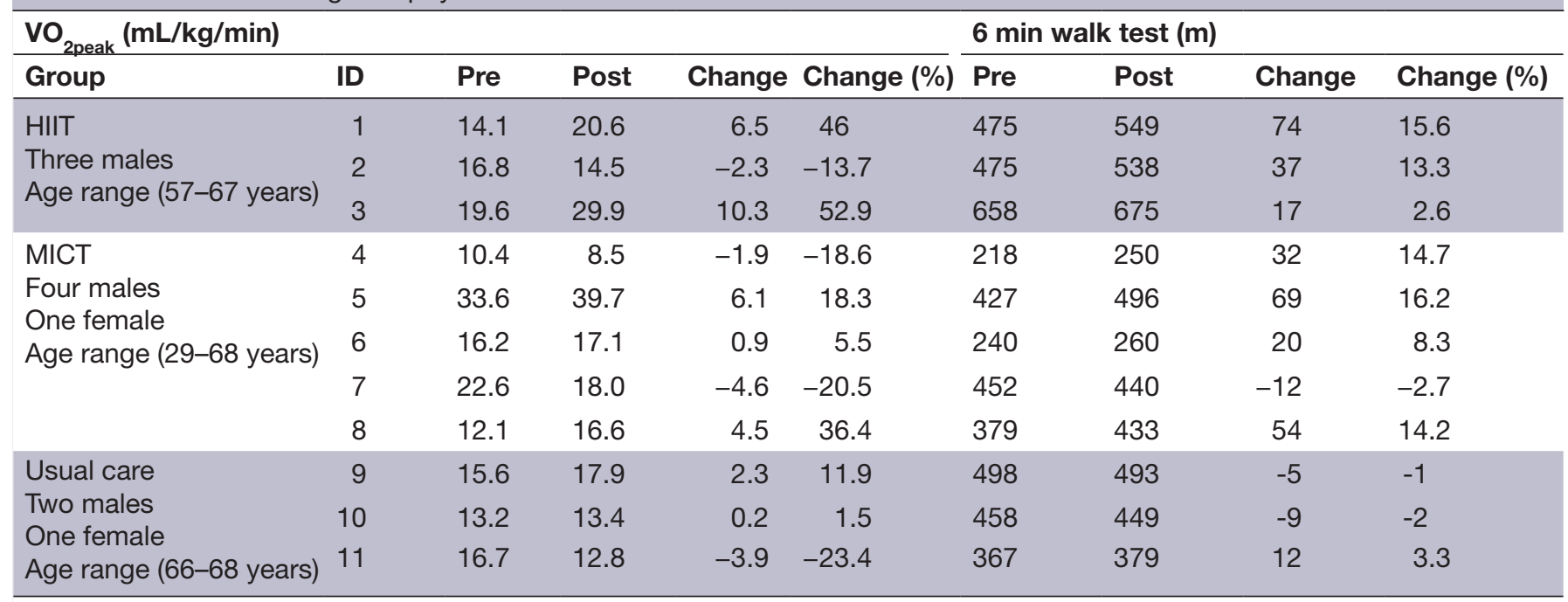

HIIT, high-intensity interval training; MICT, moderate-intensity continuous training; $6 \mathrm{MWT}, 6$ min walk test; $\mathrm{VO}_{2 \text { peak }}$, peak oxygen uptake. 
Table 3 Individual changes in health-related quality of life

\begin{tabular}{|c|c|c|c|c|c|c|c|c|c|c|c|c|c|c|c|c|c|c|c|}
\hline \multirow[b]{2}{*}{ Group } & \multirow[b]{2}{*}{ ID } & \multicolumn{3}{|c|}{ Physical fitness } & \multicolumn{3}{|c|}{ Feelings } & \multicolumn{3}{|c|}{ Daily activities } & \multicolumn{3}{|c|}{ Social activities } & \multicolumn{3}{|c|}{$\begin{array}{l}\text { Change in } \\
\text { health }\end{array}$} & \multicolumn{3}{|c|}{ Overall health } \\
\hline & & Pre & Post & $\Delta$ & Pre & Post & $\Delta$ & Pre & Post & $\Delta$ & Pre & Post & $\Delta$ & Pre & Post & $\Delta$ & Pre & Post & $\Delta$ \\
\hline \multirow[t]{3}{*}{ HIIT } & 1 & 3 & 3 & - & 4 & 4 & - & 4 & 2 & -2 & 4 & 4 & - & 3 & 2 & -1 & 4 & 3 & -1 \\
\hline & 2 & 4 & 3 & -1 & 1 & 1 & - & 2 & 1 & -1 & 1 & 1 & - & 3 & 2 & -1 & 4 & 2 & -2 \\
\hline & 3 & 3 & 1 & -2 & 1 & 1 & - & 2 & 1 & -1 & 1 & 1 & - & 2 & 1 & -1 & 2 & 2 & - \\
\hline \multirow[t]{5}{*}{ MICT } & 4 & 3 & 2 & -1 & 1 & 1 & - & 2 & 1 & -1 & 3 & 3 & - & 3 & 2 & -1 & 4 & 4 & - \\
\hline & 5 & 4 & 2 & -2 & 4 & 2 & -2 & 5 & 3 & -2 & 4 & 4 & - & 3 & 2 & -1 & 4 & 3 & -1 \\
\hline & 6 & 4 & 3 & -1 & 4 & 4 & - & 3 & 3 & - & 1 & 1 & - & 3 & 2 & -1 & 2 & 2 & - \\
\hline & 7 & 2 & 3 & +1 & 1 & 1 & - & 1 & 1 & - & 1 & 1 & - & 3 & 1 & -2 & 2 & 2 & - \\
\hline & 8 & 4 & 2 & -2 & 2 & 2 & - & 3 & 3 & - & 2 & 2 & - & 3 & 2 & -1 & 3 & 3 & - \\
\hline \multirow{3}{*}{$\begin{array}{l}\text { Usual } \\
\text { care }\end{array}$} & 9 & 2 & 3 & +1 & 1 & 1 & - & 1 & 1 & - & 1 & 1 & - & 3 & 3 & - & 1 & 2 & +1 \\
\hline & 10 & 5 & 5 & - & 4 & 5 & +1 & 3 & 1 & -2 & 5 & 2 & -3 & 3 & 3 & - & 3 & 2 & -1 \\
\hline & 11 & 3 & 3 & - & 1 & 2 & +1 & 2 & 1 & 1 & 1 & 1 & - & 3 & 3 & - & 2 & 3 & +1 \\
\hline
\end{tabular}

$\Delta$ indicates change. Reduced score indicates improved quality of life.

HIIT, high-intensity interval training; MICT, moderate-intensity continuous training.

safe and feasible exercise modality in various somatic illnesses. ${ }^{101231}$ Epidemiological studies suggests that 1 metabolic equivalent $\left(\mathrm{MET} \approx 3.5 \mathrm{~mL} / \mathrm{kg} / \mathrm{min}\right.$ ) in $\mathrm{VO}_{2 \text { peak }}$ is associated with improvement in survival by as much as $15 \%-25 \% .^{32}{ }^{33}$ Two of the three patients who completed the HIIT intervention increased their cardiorespiratory fitness by $>6.5 \mathrm{~mL} / \mathrm{kg} / \mathrm{min}$. Based on the current results, it seems that intradialytic HIIT may have considerable promise for improving cardiorespiratory fitness, which may also have an impact on survival. Existing studies have, however, not evaluated this relationship. ${ }^{34}$ It is argued that a longer duration of training may be needed to induce improvements in muscle metabolism, increase the arterial venous oxygen difference and, in turn, further improve $\mathrm{VO}_{2 \text { peak }}$ in kidney transplant recipients. ${ }^{35}$ The results from a subgroup analysis in the systematic review and the meta-analysis by Sheng et al also indicated that long-term exercise training ( $\geq 6$ months) may have more evident effects on $\mathrm{VO}_{2 \text { peak }}$ and suggests that intradialytic exercise should be conducted for a longer duration (at least 6 months). ${ }^{8}$ Our results, however, showed a potential considerable increase in $\mathrm{VO}_{2 \text { peak }}(46 \%$ and $53 \%)$ with HIIT, which can indicate the fact that HIIT can improve cardiorespiratory fitness faster and may thereby increase the motivation and adherence to exercise. ${ }^{36}$

A recent review by Parker $^{37}$ suggests future larger, multicentre trials with precise exercise intensities and durations to enhance the robustness of the evidence on intradialytic exercise. We believe that 'one size does not fit all' since the results from our study, in addition to clinical experiences, emphasise individually adapted intensity in intradialytic exercise. To be successful at maintaining adherence, some evidence suggests that interventions should be individually tailored. ${ }^{29}{ }^{38}$ In a recent qualitative study by Jhamb et al, ${ }^{29}$ it was emphasised as very important to offer an intradialytic exercise programme that could incorporate individualised exercise to the patient's health status and ability. To improve functional capacity for a heterogeneous group of patients undergoing HD, an important aspect is the physiotherapist's ability to observe the patients and to give individual feedback during and after exercise. Making exercise safe, positive and enjoyable requires a sensitive and committed physiotherapist. HIIT is shown to improve cardiorespiratory fitness more rapidly than MICT in cardiac patients ${ }^{39}$ and could therefore be more motivating in the initial phase of the exercise programme. As seen in our population, some patients responded quickly to exercise, while some used longer time and did not increase their cardiorespiratory fitness to $\geq 3.5 \mathrm{~mL} / \mathrm{kg} / \mathrm{min}$ within 16 weeks. Additionally, patients included in this pilot study continued intradialytic exercise after the post-test evaluation and reported improved HRQoL and functional capacity after a longer exercise period.

\section{Health-related quality of life}

Regarding HRQoL, six of eight patients in the intervention groups reported a clinically meaningful improvement in the domain 'physical fitness'. This is consistent with the improvements in 6MWT, except for ID 1, who did not improve in this domain; this patient, however, improved in 'daily activities', 'change in health' and 'overall health', as shown in table 3. During the follow-up period, patients who exercised had the greatest improvement on the domains physical fitness, daily activities and change in health. This corresponds to results in other studies on HRQoL of intradialytic exercise ${ }^{4041}$ and is an important outcome, given the population's poor HRQoL. ${ }^{2}$

\section{Strengths and limitations}

The strengths of our study are the RCT study design and the use of CPET for measurement of the $\mathrm{VO}_{\text {2peak }}$. 
The main limitations of our trial are the low number of patients and heterogenicity with respect to age, aetiology of chronic kidney disease, disease burden and cardiorespiratory fitness at baseline. Anyhow, the data confirm that it is feasible to introduce intradialytic exercise with HIIT in a heterogeneous and medically stable HD population, but with individualisation of the programme supervised by an experienced physiotherapist. The drop-out rate due to kidney transplant was higher than anticipated, and the power to detect differences between study groups was limited.

\section{CONCLUSIONS}

This pilot study demonstrated that HIIT is a feasible and safe exercise model for intradialytic exercise in patients undergoing HD. Our study cannot conclude if HIIT is superior to MICT during HD due to the small sample size. The results showed, however, a considerable increase in $\mathrm{VO}_{2 \text { peak }}$ in selected patients and emphasised the importance of intradialytic exercise. Hopefully, our findings may contribute to guide future research on HIIT with larger sample sizes to determine if there is an optimal exercise intensity approach to intradialytic exercise.

Contributors All authors were involved in the study design and in the draft of this report.

Funding This work was supported with funding of salary to HB-N by The Norwegian Fund for Post-Graduate Training in Physiotherapy and the Norwegian Extra Foundation for Health and Rehabilitation.

Competing interests EE received salary from GlaxoSmithKline with no potential conflicts of interest with respect to the research, authorship and/or publication of this article.

Patient consent for publication Not required.

Ethics approval The study was approved by the Regional Committee for Medical and Health Research Ethics (2012/1459) and by the data inspectorate at Oslo University Hospital. Written and oral information was provided, and informed signed consent was required before participating.

Provenance and peer review Not commissioned; externally peer reviewed.

Data availability statement All data relevant to the study are included in the article or uploaded as supplementary information.

Open access This is an open access article distributed in accordance with the Creative Commons Attribution Non Commercial (CC BY-NC 4.0) license, which permits others to distribute, remix, adapt, build upon this work non-commercially, and license their derivative works on different terms, provided the original work is properly cited, appropriate credit is given, any changes made indicated, and the use is non-commercial. See: http://creativecommons.org/licenses/by-nc/4.0/.

ORCID iD

Birgitta Blakstad Nilsson http://orcid.org/0000-0003-0892-1130

\section{REFERENCES}

1 Johansen KL, Chertow GM, Da Silva M, et al. Determinants of physical performance in ambulatory patients on hemodialysis. Kidney Int 2001;60:1586-91.

2 Wang R, Tang C, Chen X, et al. Poor sleep and reduced quality of life were associated with symptom distress in patients receiving maintenance hemodialysis. Health Qual Life Outcomes 2016;14:125.

3 Greenwood SA, Naish P, Clark R, et al. INTRA-DIALYTIC exercise training: a pragmatic approach. J Ren Care 2014;40:219-26.

4 Konstantinidou E, Koukouvou G, Kouidi E, et al. Exercise training in patients with end-stage renal disease on hemodialysis: comparison of three rehabilitation programs. J Rehabil Med 2002;34:40-5.

5 Painter P. Physical functioning in end-stage renal disease patients: update 2005. Hemodial Int 2005;9:218-35.
6 Salhab N, Karavetian M, Kooman J, et al. Effects of intradialytic aerobic exercise on hemodialysis patients: a systematic review and meta-analysis. J Nephrol 2019;32:549-66.

7 Johansen KL. Exercise in the end-stage renal disease population. JASN 2007;18:1845-54.

8 Sheng K, Zhang P, Chen L, et al. Intradialytic exercise in hemodialysis patients: a systematic review and meta-analysis. $A m \mathrm{~J}$ Nephrol 2014;40:478-90.

9 Weston M, Taylor KL, Batterham AM, et al. Effects of low-volume high-intensity interval training (HIT) on fitness in adults: a metaanalysis of controlled and non-controlled trials. Sports Med 2014;44:1005-17.

10 Tjønna AE, Lee SJ, Rognmo Øivind, et al. Aerobic interval training versus continuous moderate exercise as a treatment for the metabolic syndrome: a pilot study. Circulation 2008;118:346-54.

11 Rognmo Øivind, Hetland E, Helgerud J, et al. High intensity aerobic interval exercise is superior to moderate intensity exercise for increasing aerobic capacity in patients with coronary artery disease. Eur J Cardiovasc Prev Rehabil 2004;11:216-22.

12 Wisløff U, Støylen A, Loennechen JP, et al. Superior cardiovascular effect of aerobic interval training versus moderate continuous training in heart failure patients. Circulation 2007;115:3086-94.

13 Nilsson BB, Westheim A, Risberg MA. Long-Term effects of a groupbased high-intensity aerobic interval-training program in patients with chronic heart failure. Am J Cardiol 2008;102:1220-4.

14 Beetham KS, Howden EJ, Fassett RG, et al. High-Intensity interval training in chronic kidney disease: a randomized pilot study. Scand J Med Sci Sports 2019;29:1197-204.

15 Borg GAV. Psychophysical bases of perceived exertion. Med Sci Sports Exerc 1982;14:377-81.

16 Taylor JL, Holland DJ, Spathis JG, et al. Guidelines for the delivery and monitoring of high intensity interval training in clinical populations. Prog Cardiovasc Dis 2019;62:140-6.

17 Nilsson BB, Hellesnes B, Westheim A, et al. Group-Based aerobic interval training in patients with chronic heart failure: Norwegian Ullevaal model. Phys Ther 2008;88:523-35.

18 Nilsson BB, Lunde P, Holm I. Implementation and evaluation of the Norwegian Ullevaal model as a cardiac rehabilitation model in primary care. Disabil Rehabil 2017:1-8.

19 Ingjer F. Factors influencing assessment of maximal heart rate. Scand J Med Sci Sports 1991;1:134-40.

20 Laboratories ATSCoPSfCPF. Ats statement: guidelines for the sixminute walk test. Am J Respir Crit Care Med 2002;166:111-7.

21 Regueiro EMG, Pires Di Lorenzo VA, Basso RP, et al. Relationship of bode index to functional tests in chronic obstructive pulmonary disease. Clinics 2009;64:983-8.

22 Guimarães GV, Carvalho VO, Bocchi EA. Reproducibility of the selfcontrolled six-minute walking test in heart failure patients. Clinics 2008;63:201-6.

23 Broderick J, Mc Grath C, Cullen K, et al. Effects of pulmonary rehabilitation on exercise capacity and disease impact in patients with chronic obstructive pulmonary disease and obesity. Physiotherapy 2018;104:248-250.

24 Hsieh R-L, Lee W-C, Chang C-H. Maximal cardiovascular fitness and its correlates in ambulatory hemodialysis patients. Am J Kidney Dis 2006;48:21-7.

25 Kohl LM, Signori LU, Ribeiro RA, et al. Prognostic value of the six-minute walk test in end-stage renal disease life expectancy: a prospective cohort study. Clinics 2012;67:581-6.

26 Bruusgaard DAG, Nessioy I, Rutle O, et al. Measuring functional status in a population survey. The Dartmouth coop functional health assessment charts/WONCA used in an epidemiological study. Fam Pract 1993;10:212-8.

27 Martín-Díaz F, Reig-Ferrer A, Ferrer-Cascales R. Assessment of health-related quality of life in chronic dialysis patients with the COOP/WONCA charts. Nephron Clin Pract 2006;104:c7-14.

28 Lam CL, Lauder IJ, Lam DT. How does a change in the administration method affect the reliability of the COOP/WONCA charts? world organization of national colleges, academies and academic associations of general Practitioners/Family physicians. Fam Pract 1999;16:184-9.

29 Jhamb M, McNulty ML, Ingalsbe G, et al. Knowledge, barriers and facilitators of exercise in dialysis patients: a qualitative study of patients, staff and nephrologists. BMC Nephrol 2016;17:192.

30 Norwegian Renal Registry. Annual report 2016, 2016. Available: http://www.nephro.no/registry.html

31 Nytrøen K, Rustad LA, Aukrust P, et al. High-Intensity interval training improves peak oxygen uptake and muscular exercise capacity in heart transplant recipients. Am J Transplant 2012;12:3134-42. 
32 Myers J, Prakash M, Froelicher V, et al. Exercise capacity and mortality among men referred for exercise testing. $N$ Engl J Med 2002;346:793-801.

33 Gulati M, Pandey DK, Arnsdorf MF, et al. Exercise capacity and the risk of death in women: the ST James women take heart project. Circulation 2003;108:1554-9.

$34 \mathrm{Pu} \mathrm{J}$, Jiang Z, Wu W, et al. Efficacy and safety of intradialytic exercise in haemodialysis patients: a systematic review and metaanalysis. BMJ Open 2019;9:e020633.

35 Painter PL, Nelson-Worel JN, Hill MM, et al. Effects of exercise training during hemodialysis. Nephron 1986;43:87-92.

36 Weston KS, Wisløff U, Coombes JS. High-Intensity interval training in patients with lifestyle-induced cardiometabolic disease: a systematic review and meta-analysis. Br J Sports Med 2014;48:1227-34.

37 Parker K. Intradialytic exercise is medicine for hemodialysis patients. Curr Sports Med Rep 2016;15:269-75.
38 Amro A, Waldum B, Dammen T, et al. Symptom clusters in patients on dialysis and their association with quality-of-life outcomes. $J$ Ren Care 2014:40:23-33.

39 Liou K, Ho S, Fildes J, et al. High intensity interval versus moderate intensity continuous training in patients with coronary artery disease: a meta-analysis of physiological and clinical parameters. Heart Lung Circ 2016;25:166-74.

$40 \mathrm{Wu} \mathrm{Y}, \mathrm{He} \mathrm{Q}$, Yin $\mathrm{X}$, et al. Effect of individualized exercise during maintenance haemodialysis on exercise capacity and healthrelated quality of life in patients with uraemia. $J$ Int Med Res 2014;42:718-27.

41 Ouzouni S, Kouidi E, Sioulis A, et al. Effects of intradialytic exercise training on health-related quality of life indices in haemodialysis patients. Clin Rehabil 2009;23:53-63. 